Syarifah Aini dan Erlin Widya Fatmawati, 2017. Analisis Usaha Home Industri Kerupuk Rambak

Journal Viabel Pertanian. (2017), 11(2) 35-45

\title{
ANALISIS USAHA HOME INDUSTRI KERUPUK RAMBAK
}

\author{
Syarifah Aini ${ }^{1}$ ) dan Erlin Widya Fatmawati ${ }^{2)}$
}

1) Mahasiswa prodi Agribisnis, Fakultas Pertanian, Universitas Islam Balitar

2) Dosen prodi Agribisnis, Fakultas Pertanian, Universitas Islam Balitar

\begin{abstract}
The purpose of this research is to know the amount of cost, acceptance, profit, profitability, and R / C Ratio from home industry crackers rambak in Sembon Village Satreyan District Kanigoro Blitar District. The result of this research shows that the total variable cost at rambak cracker agroindustry center is equal to Total variable cost Rp 1,139,783, - per day, total fixed cost Rp 4,953, per day. So the total total cost of production is Rp 1,144,076, - per month. The breakeven point or BEP unit is 3 units. BEP Rp for RP 16,017, -. BEP revenue of $\mathrm{Rp} 16,017$, - per day. Received revenue of $\mathrm{Rp} 1.650 .000$, - so the profit earned by employers is amounted to $\mathrm{Rp} 505,924$, -. While the profitability of business is $44 \%$ which means this business is profitable. Home industry that run during this efficiency has been shown with $\mathrm{R} / \mathrm{C}$ ratio of more than 1 that is equal to 1.44. Based on the criteria used, this business has been efficient because the efficiency value of more than 1 . This means that every Rp 1.00 issued by the entrepreneur at the beginning of the business activities will get 1.44 times revenue from the cost incurred at the end of the business activity. This can be interpreted that home industry crackers rambak said Eligible to run. From this research it is suggested that entrepreneurs do creations by adding a sense of the product, so that the quality of the product can be increased and not less competitive with similar entrepreneurs from other regions. For the government, the Government of Blitar Regency through the Department of Industry and Trade and other related agencies should try to help develop the business crackers rambak by providing low-interest capital loans to entrepreneurs agro-industry crackers rambak.
\end{abstract}

\section{Keyword : R/C ratio, BEP}

\section{LATAR BELAKANG}

Pembangunan ekonomi di Indonesia menitik beratkan pada industri dan pertanian yang berbasis agroindustri. Dalam agribisnis, agroindustri adalah salah satu subsistem yang bersama-sama subsistem lain membentuk agribisnis, terdiri dari input dan out put, dengan demikian sistim agroindustri tidak dapat lepas dari pembangunan agribisnis secara keseluruhan. Pembangunan agroindustriakan dapat meningkatkan produksi, harga hasil pertanian, serta dapat menghasilkan nilai tambah dari hasil pertanian. 
Jurnal Viabel Pertanian Vol. 11 No.1 Mei 2017

p-ISSN: 1978-5259 e-ISSN: 2527-3345

Copyright@UNISBA Blitar, http://viabel.unisbablitar.ejournal.web.id

Syarifah Aini dan Erlin Widya Fatmawati, 2017. Analisis Usaha Home Industri Kerupuk Rambak

Journal Viabel Pertanian. (2017), 11(2) 35-45

Dalam mengusahakan suatu industri, pengusaha mempunyai tujuan yang ingin dicapai yaitu bagaimana usaha yang dilakukan tersebut akan dapat memberikan keuntungan dengan menggunakan sumber daya yang ada. Pengusaha berusaha untuk mengalokasikan penggunaan sumber daya tersebut sebaik-baiknya agar diperoleh keuntungan yang sebesar-besarnya.Begitu juga dengan pengusaha pada sentra industri kecil kerupuk rambak dalam melakukan usahanya menginginkan keuntungan yang sebesar-besarnya, walaupun banyak risiko yang harus dihadapi. Risiko yang dimaksud yaitu fluktuasi harga bahan baku, musim hujan yang bias memperlambat proses produksi dan fluktuasi harga jual produk.

Industri kerupuk rambak ini merupakan home industtri. Usaha kerupuk ini memiliki peluang yang besar untuk di kembangkan baik untuk konsumsi dalam negeri maupun untuk ekspor. Melihat prospek usaha kerupuk, maka usaha kerupuk rampak ini perlu penanganan yang tepat agar kedepannya dapat berkembang dan mampu bersaing dengan usaha sejenis.

1. Mengetahui besarnya biaya, penerimaan, keuntungan dan profitabilitas pada usaha home industri kerupuk rambak di Desa Sembon Kelurahan Satreyan Kecamatan Kanigoro Kabupaten Blitar.

2. Mengetahui besarnya tingkat efisiensi pada home industri kerupuk rambak di Desa Sembon Kelurahan Satreyan Kecamatan Kanigoro Kabupaten Blitar.

\section{METODE PENELITIAN}

\section{TEMPAT DAN WAKTU}

Penelitian ini dilakukan pada home industri kerupuk rambak yang beralamatkan Desa sembon Kelurahan Satreyan Kecamatan Kanigoro Kabupaten Blitar. penelitian ini dipilh secara sengaja (purposive), dengan pertimbangan bahwa industri kecil ini mampu bertahan ditengah persaingan usaha kerupuk rambak yang semakin bertambah. Sedangkan tingkat permintaan pada industri kerupuk rambak tersebut pada titik yang tinggi. Penelitin ini di lakukan selama satu bulan ( juni 2017). 
Jurnal Viabel Pertanian Vol. 11 No.1 Mei 2017

p-ISSN: 1978-5259 e-ISSN: 2527-3345

Copyright@UNISBA Blitar, http://viabel.unisbablitar.ejournal.web.id

Syarifah Aini dan Erlin Widya Fatmawati, 2017. Analisis Usaha Home Industri Kerupuk Rambak

Journal Viabel Pertanian. (2017), 11(2) 35-45

\section{Metode pengumpulan data}

Data yang diperoleh berupa data kualitatif dan data kuantitatif dilakukan untuk mengetahui karakteristik agroindustri kerupuk rambak yang disajikan pada aspek aspek finansial dalam bentuk uraian deskriptif, table, bagan, atau gambar untuk mempermudah pemahaman.

Pengumpulan data dan keterangan yang diperlukan dalam penelitian ini melalui beberapa cara, yaitu: Data primer ( Observasi, Wawancara, Pencatatan). Data sekunder ( proses membaca, penelitian terdahulu, mempelajari dan mengambil keterangan dari buku bahan bahan kuliah serta sumber sumber data yang lainnya yang berhubungan dengan masalah yang akan diteliti).

Sedangkan data kuantitatif disajikan untuk mengetahui keadaan agroindustri secara financial seperti untuk mengetahui apakah pelaksanaan suatu agroindustri tersebut menguntungkan atau tidak, maka perlu dilakukan evaluasi proyek dengan cara menghitung manfaat dan biaya yang diperlukan sepanjang umur perusahaan. Setelah dilakukan identifikasi terhadap semua manfaat dan biaya, maka baru dapat dilakukan perhitungan untuk mendapatkan nilai dari kriteria investasi. Adapun metode yang digunakan dalam analisis usaha pada agroindustri krupuk rambak ini adalah sebagai berikut :

a. Nilai total biaya pada agroindustri krupuk rambak adalah penjumlahan dari nilai total biaya tetap (TFC) dan nilai biaya variabel atau biaya tidak tetap (TVC) yang digunakan dalam kegiatan produksi. Secara matematis dirumuskan sebagai berikut :

$$
\mathbf{T C}=\mathbf{T F C}+\mathbf{T V C}
$$

b. Untuk mengetahui penerimaan pada agroindustri krupuk rambak yaitu dengan mengalikan jumlah produksi (terjual) dengan harga. Secara matematis dirumuskan sebagai berikut :

$\mathbf{T R}=\mathbf{Q} \times \mathbf{P}$

c. Keuntungan usaha adalah selisih antara penerimaan total dengan biaya total. Secara matematis dirumuskan sebagai berikut :

$$
\pi \quad \mathbf{T R}-\mathbf{T C}
$$

dimana 
Jurnal Viabel Pertanian Vol. 11 No.1 Mei 2017

p-ISSN: 1978-5259 e-ISSN: 2527-3345

Copyright@UNISBA Blitar, http://viabel.unisbablitar.ejournal.web.id

Syarifah Aini dan Erlin Widya Fatmawati, 2017. Analisis Usaha Home Industri Kerupuk Rambak

Journal Viabel Pertanian. (2017), 11(2) 35-45

$\pi \quad=$ keuntungan agroindustri krupuk rambak (Rupiah)

$\mathrm{TR}=$ penerimaan total agroindustri krupuk $\operatorname{rambak}(\operatorname{Rupiah})$

TC = biaya total agroindustri krupuk rambak (Rupiah).

$\mathrm{TFC}=$ total biaya tetap agroindustri krupuk rambak (Rupiah)

$\mathrm{TVC}=$ total biaya variabel atau tidak tetap agroindustri krupuk rambak (Rupiah).

$\mathrm{TR}=$ penerimaan total agroindustri krupuk rambak (Rupiah)

$\mathrm{Q}=$ jumlah krupuk rambak yang terjual $(\mathrm{kg})$

$\mathrm{P} \quad=$ harga krupuk rambak (Rupiah) per kg (Rupiah)

d. BEP ( Break Even Point )

Menurut Soekartawi (2006) dalam Reny (2010), analisis BEP atau nilai impas adalah suatu teknis analisis untuk mempelajari hubungan antara biaya tetap, biaya variable, keuntungan, volume penjualan BEP dalam penelitian merupakan pengukuran dimana kapasitas riil pengolahan bahan baku menjadi output menghasilkan total penerimaan yang sama dengan pengeluaran BEP dalam unit dan dalam rupiah.

e. R/C Rasio

$\mathrm{R} / \mathrm{C}$ Ratio adalah jumlah ratio yang di gunakan untuk melihat keuntungan relatif yang akan didapatkan dalam sebuah proyek. Pada dasarnya, sebuah proyek akan dikatakan layak untuk dijalankan apabila nilai $\mathrm{R} / \mathrm{C}$ dari sebuah agroindustri, maka tingkat keuntungan yang akan didapatkan suatu proyek juga akan srmakin tinggi.

Rumus yang digunakan untuk melakukan perhitungan nilai R/C Ratio adalah

$\mathrm{R} / \mathrm{C}=$ Penerimaan $:$ Total Biaya

\section{HASIL DAN BAHASAN}

\section{ANALISIS BIAYA}

Biaya yang dimaksud dalam penelitian ini adalah seluruh biaya yang digunakan untuk pembuatan kerupuk rambak dikeluarkan oleh pengusaha. Seluruh biaya yang 
Jurnal Viabel Pertanian Vol. 11 No.1 Mei 2017

p-ISSN: 1978-5259 e-ISSN: 2527-3345

Copyright@UNISBA Blitar, http://viabel.unisbablitar.ejournal.web.id

Syarifah Aini dan Erlin Widya Fatmawati, 2017. Analisis Usaha Home Industri Kerupuk Rambak

Journal Viabel Pertanian. (2017), 11(2) 35-45

dikeluarkan tersebut digolongkan kedalam dua golongan, yaitu biaya tetap dan biaya tidak tetap.

\section{Biaya Tetap}

Biaya tetap adalah biaya yang digunakan dalam agroindustri krupuk rambak yang besarnya tidak dipengaruhi oleh jumlah produk yang dihasilkan.Biaya tetap dalam usaha pada agroindustri krupuk rambak meliputi biaya penyusutan peralatan, dan bunga modal investasi. Biaya penyusutan peralatan dan biaya tenaga kerja, energy dan perawatan.

\section{a. Penyusutan Alat}

Besarnya biaya penyusutan peralatan dapat dihitung dengan rumus :

Penyusutan/Bulan $=$ Nilai Investasi Awal $\mathrm{x}$ jumlah alat Umur Ekonomis (Bulan)

Rata-rata biaya tetap dapat dilihat pada tabel berikut ini:

Table 3 Biaya penyusutan Mesin Atau Alat

\begin{tabular}{lllllll}
\hline No & Teknologi & Satuan & Harga(Rp) & $\begin{array}{l}\text { Jumlah } \\
(\mathbf{R p})\end{array}$ & $\begin{array}{l}\text { umur } \\
\text { ekonomis }\end{array}$ & Biaya penyusuta (Rp) \\
\hline 1 & Ketel & 1 & $10.000 .000,-$ & $10.000 .000,-$ & 15 & $666.666,-$ \\
2 & Pengukus & 1 & $9.000 .000,-$ & $9.000 .000,-$ & 15 & $600.000,-$ \\
3 & bak besar & 3 & $2.0000,-$ & $60.000,-$ & 10 & $6.000,-$ \\
4 & Loyang & 100 & $1.0000,-$ & $1.000 .000,-$ & 20 & $50.000,-$ \\
5 & Rigen & 100 & $5,000,-$ & $500.000,-$ & 15 & $33.333,-$ \\
6 & Sudet & 4 & 1500 & $6.000,-$ & 5 & $1.200,-$ \\
7 & Blender & 1 & 350000 & $350.000,-$ & 10 & $35.000,-$ \\
8 & Pengaduk & 1 & 150000 & $150.000,-$ & 10 & $15.000,-$ \\
& alat & & & & \\
9 & pemotong & 1 & 750000 & $750.000,-$ & 15 & $50.000,-$ \\
10 & Terpal & 2 & 200000 & $400.000,-$ & 10 & $40.000,-$ \\
11 & Pisau & 2 & 15000 & $30.000,-$ & 15 & $2.000,-$ \\
12 & Telenan & 2 & 10000 & $20.000,-$ & 15 & $1.333,-$ \\
13 & Impulse & 1 & 450000 & $450.000,-$ & 10 & $45.000,-$ \\
Total 1 tahun & & & & $1.545 .533,-$ \\
Total 1 bulan & & & & $128.794,-$ \\
\hline \multicolumn{7}{l}{ Total 1 hari } \\
\hline
\end{tabular}


Jurnal Viabel Pertanian Vol. 11 No.1 Mei 2017

p-ISSN: 1978-5259 e-ISSN: 2527-3345

Copyright@UNISBA Blitar, http://viabel.unisbablitar.ejournal.web.id

Syarifah Aini dan Erlin Widya Fatmawati, 2017. Analisis Usaha Home Industri Kerupuk Rambak

Journal Viabel Pertanian. (2017), 11(2) 35-45

Sumber : Data primer diolah,2017

Tabel 3 menunjukan bahwa total rata-rata biaya penyusutan alat sebebsar Rp $4.953,-$. Jadi total biaya tetap yang didapat dari penjumlahan biaya penyusutan alat adalah sebesar Rp 4.953,-per hari. Biaya Variabel

\section{a. Biaya Bahan Baku}

Table 4 Biaya Bahan Baku dan Penunjang

\begin{tabular}{|c|c|c|c|c|c|}
\hline No & Bahan & Satuan & jumlah & $\begin{array}{l}\text { harga satuan } \\
\text { (Rp ) }\end{array}$ & Harga (Rp) \\
\hline 1 & tepung kanji & $\mathrm{Kg}$ & 100 & $5.000,-$ & $500.000,-$ \\
\hline 2 & Tepung Terigu & $\mathrm{Kg}$ & 50 & $4.500,-$ & $225.000,-$ \\
\hline 3 & Bawang & $\mathrm{Kg}$ & 1 & $28.000,-$ & $28.000,-$ \\
\hline 4 & Udang kering & $\mathrm{Kg}$ & 1 & $50.000,-$ & $50.000,-$ \\
\hline 5 & $\begin{array}{l}\text { Garam } \\
\text { Pewarna }\end{array}$ & $\mathrm{Kg}$ & 4 & $4.500,-$ & 18.000,- \\
\hline 6 & $\begin{array}{l}\text { makanan } \\
\text { penyedap }\end{array}$ & $\mathrm{Sdm}$ & 1 & $2.000,-$ & $2.000,-$ \\
\hline 7 & makanan & Bungkus & 1 & $9.000,-$ & $9.000,-$ \\
\hline 8 & Plastik & Rol & 1 & $75.000,-$ & $75.000,-$ \\
\hline 9 & Label & Biji & 30 & $15,-$ & $450,-$ \\
\hline 10 & bahan bakar & Karung & 2 & $2.500,-$ & $5.000,-$ \\
\hline 11 & Biaya distribusi & & & $5.000,-$ & $5.000,-$ \\
\hline \multicolumn{4}{|c|}{ Jumlah per produksi } & & 5912.45 \\
\hline
\end{tabular}

Tabel 4 menunjukkan bahwa biaya bahan baku yang dikeluarkan pengusaha agroindustri krupuk rambak selama satu hari yaitu Rp 912.450,-. Untuk biaya distribusi atau transport selama 1 hariyaitu sebesar Rp 5.000,-. Jadi, jumlah total biaya bahan baku dan distribusi yang dikeluarkan agroindustri krupuk rambak selama 1 bulan yaitu sebesar Rp 917.450,-. Kapasitas produksi $150 \mathrm{~kg}$ bahan mentah menjadi $150 \mathrm{~kg}$ krupuk rambak dikemas@5kg=30 kemasan. Jadi dalam 1 hari memproduksi 30 kemasan.

\section{b. Biaya Tenaga Kerja}

Table 5 Biaya Tenaga Kerja

\begin{tabular}{llllll}
\hline No & Nama & Satuan & $\begin{array}{l}\text { Jumlah } \\
\text { Kebutuhan }\end{array}$ & $\begin{array}{l}\text { Biaya } \\
(\mathrm{Rp})\end{array}$ & Satuan \\
\hline
\end{tabular}


Jurnal Viabel Pertanian Vol. 11 No.1 Mei 2017

p-ISSN: 1978-5259 e-ISSN: 2527-3345

Copyright@UNISBA Blitar, http://viabel.unisbablitar.ejournal.web.id

Syarifah Aini dan Erlin Widya Fatmawati, 2017. Analisis Usaha Home Industri Kerupuk Rambak

Journal Viabel Pertanian. (2017), 11(2) 35-45

\begin{tabular}{rrrll}
\hline 1 & Tenaga kerja & Orang 7 & $30.000,-$ & $210.000,-$ \\
\hline Jumlah Perproduksi & & & $\mathbf{2 1 0 , - 0 0 0 , -}$ \\
\hline
\end{tabular}

Sumber : Data primer diolah, 2017

Tabel 5 menunjukan biaya tenaga kerja agroindustri Kerupuk Rambak yang harus dikeluarkan sebesar Rp 210.000,-per hari. Dengan biaya tenaga kerja satuanya 30.000,-. Total jumlah tenaga kerja7 orang.

\section{c. Biaya Operasional}

Table 6 Biaya Energy listrik, Telepon, Perawatan dan Transportasi

\begin{tabular}{llllll}
\hline No & Nama & Satuan & $\begin{array}{l}\text { Jumlah } \\
\text { kebutuhan }\end{array}$ & Biaya satuan & Biaya \\
\hline 1 & Listrik & Bulan & 1 & 30000 & $30.000,-$ \\
2 & Telepon & Bulan & 1 & 30000 & $30.000,-$ \\
3 & Perawatan & Bulan & 1 & 10000 & $10.000,-$ \\
4 & Transportasi & Bulan & 1 & 450000 & $450.000,-$ \\
Total 1 bulan & & & & $520.000,-$ \\
\hline Total 1 Produksi & & & & $\mathbf{1 7 . 3 3 3 , -}$ \\
\hline
\end{tabular}

Sumber : Data primer diolah, 2017

Tabel 6 menunjukan bahwa total biaya energi listrik, telepon perawatan dan transportasi pada agroindustri sebesar Rp 520.000,-. Dengan biaya listrik satu bulan Rp $30.000,-$, , biaya telepon satu bulan Rp 30.000,-, biaya perawatan Rp 10.000,-, dan biaya transportasi Rp 45.000,-. Jumlah tersebut dijadikan perhari menjadi Rp 17.333,-

Total jumlah biaya variabel yang harus dikeluarkan agroindustri adalah sebesar Rp1.139.783,- Hasil tersebut didapat dari penjumlahan biaya bahan baku, biaya tenaga kerja dan biaya energi listrik, telepon, perawatan dan trasportasi.

Biaya Total

Biaya total adalah hasil dari penjumlahan seluruh biaya tetap dan biaya tidak tetap yang dikeluarkan selama proses produksi. Biaya total yang dikeluarkan agroindustri krupuk rambak selama 1 bulan yaitu sebagai berikut:

Total biaya = biaya variabel + biaya tetap 
Syarifah Aini dan Erlin Widya Fatmawati, 2017. Analisis Usaha Home Industri Kerupuk Rambak

$=\operatorname{Rp} 1.139 .783,-+\mathbf{R p} 4.953,-$

$=$ Rp 1.144.076,-

Jumlah biaya total yang diperoleh sebesar Rp 1.144.076,-

\section{ANALISIS EFISIENSI}

\section{Penerimaan}

Penerimaan $=$ harga produk $\mathrm{x}$ jumlah produk

$=\operatorname{Rp} 55.000,-\mathrm{x} 30$

$=$ Rp 1.650.000,-

Penerimaan agroindustri krupuk rambak selama 1 bulan dengan biaya total $\mathrm{Rp}$ 1.144.076,-yaitu sebesar Rp 1.650.000,-.

\section{Keuntungan}

$$
\begin{aligned}
\text { Keuntungan } & =\text { pendapatan }- \text { total biaya } \\
& =\text { Rp } 1.650 .000,--\operatorname{Rp~} 1.144 .076,- \\
& =\text { Rp 505.924,- }
\end{aligned}
$$

Keuntungan agroindustri krupuk rambak selama 1 bulan dengan total biayaRp

1.144.076,- yaitu sebesar Rp 505.924,-

\section{Profitabilitas}

Profitabilitas merupakan hasil bagi antara keuntungan usaha dengan biaya total yang dinyatakan dalam persen. Untuk mengetahui besarnya profitabilitas pada agroindustri krupuk rambak dapat dilihat pada perhitungan berikut:

$$
\begin{aligned}
\text { Profitabilitas } & =\frac{\pi \times 100 \%}{T C} \\
\text { Profitabilitas }= & \frac{\operatorname{Rp~505.926,-} \times 100 \%}{\operatorname{Rp~} 1.144 .076,-}
\end{aligned}
$$

Profitabilitas $=44,22=44 \%$ (dibulatkan) 
Syarifah Aini dan Erlin Widya Fatmawati, 2017. Analisis Usaha Home Industri Kerupuk Rambak

Journal Viabel Pertanian. (2017), 11(2) 35-45

Perhitungan diatas menunjukkan bahwa profitabilitas atau tingkat keuntungan pada agroindustri krupuk rambak adalah sebesar 44\%. Hal ini berarti setiap modal sebesar Rp 1,00 yang diinvestasikan akan diperoleh keuntungan $44 \%$. Misal, awalnya pengusaha mengeluarkan modal sebesar $\mathrm{Rp}$ 100.000,00 maka pengusaha akan memperoleh keuntungan sebesar Rp 44.000,-.

\subsubsection{BEP}

BEP dalam unit dan dalam rupiah pada agroindustri krupuk dapat dilihat pada perhitungan berikut:

$$
\text { BEP unit }=\frac{4.953,-}{\left[55.000,--\left(\frac{1.139 .783,-}{30}\right)\right]}
$$

$\mathrm{BEP}$ unit $=3,421=3$ unit.

Usaha agroindustri kerupuk rambak akan mengalami BEP ketika dapat produksi 9 unit.

$$
\text { BEP Rp }=\frac{\operatorname{Rp} 4.953,-}{\left[1-\left(\frac{\operatorname{Rp} 1.139 .783,-/ 30}{\operatorname{Rp} 55.000,-}\right)\right]}
$$

BEP Rp = Rp 16.017,-

Usaha agroindustri kerupuk rambak akan mengalami BEP harga ketika harga kerupuk Rp 16.017,-. Pemilik menjual produknya Rp 55.000,- / unit. Jadi usaha sudah dikatakan layak.

\subsubsection{5 $\mathrm{R} / \mathrm{C}$ rasio}

Rumus yang digunakan untuk melakukan perhitungan nilai R/C Ratio adalah

$$
\begin{aligned}
\mathrm{R} / \mathrm{C} & =\text { Penerimaan }: \text { Total Biaya } \\
& =\mathrm{Rp} 1.650 .000: \operatorname{Rp} 1.144 .076,-
\end{aligned}
$$


Jurnal Viabel Pertanian Vol. 11 No.1 Mei 2017

p-ISSN: 1978-5259 e-ISSN: 2527-3345

Copyright@UNISBA Blitar, http://viabel.unisbablitar.ejournal.web.id

Syarifah Aini dan Erlin Widya Fatmawati, 2017. Analisis Usaha Home Industri Kerupuk Rambak

Journal Viabel Pertanian. (2017), 11(2) 35-45

$$
=1,44
$$

Berdasarkan perhitungan diatas dapat diketahui bahwa nilai efisiensi usaha atau $\mathrm{R} / \mathrm{C}$ ratio pada agroindustri krupuk rambak sebesar 1,44. Berdasarkan kriteria yang digunakan, maka usaha ini sudah efisien karena nilai efisiensi lebih dari 1. Nilai efisiensi usaha 1,62 berarti bahwa setiap 1 rupiah biaya yang dikeluarkan oleh pengusaha akan didapatkan penerimaan 1,62 kali biaya yang telah dikeluarkan tersebut. Karena nilai R/CRatio> 1, maka usaha ini layak untuk terus dijalankan.

\section{SIMPULAN}

Berdasarkan hasil penelitian dan analisis yang telah dilakukan, maka dapat diperoleh kesimpulan sebagai berikut :

1.Total biaya variabel pada sentra agroindustri kerupuk rambak milik Bu Nuriyah adalah sebesar Total biaya variabel Rp 1.139.783,-perhari, total biaya tetapRp 4.953,- perhari. Jadi Total biaya keseluruhan produki sebesar Rp 1.144.076,-perbulan.Titik impas atau BEP unit sebesar 3 unit. BEP Rp sebesarRp 16.017,-. BEP penerimaan sebesar Rp 16.017,-- per hari.Penerimaan yang diperoleh sebesar Rp 1.650.000,- sehingga keuntungan yang diperoleh pengusaha adalah sebesarRp 505.924,-. Sedangkan profitabilitas usaha adalah sebesar $44 \%$ yang berarti usaha ini menguntungkan. Apabila pada saat awal usaha para pengusaha mengeluarkan modal sebesar Rp 100.000,00 maka pengusaha akan memperoleh keuntungan sebesar Rp 44.000,-.

2.Usaha pada Agroindustri krupuk rambak milik Bu Nuriyah mempunyai nilai efisiensi lebih dari satu yaitu sebesar 1,44. Berdasarkan kriteria yang digunakan, maka usaha ini sudah efisien karena nilai efisiensi lebih dari 1. Hal ini berarti bahwa setiap Rp 1,00 yang dikeluarkan pengusaha pada awal kegiatan usaha akan mendapatkan penerimaan 1,44 kali dari biaya yang dikeluarkan pada akhir kegiatan usaha tersebut.

\section{PUSTAKA}

Ali Musa 2012. Perencanaan dan Evaluasi Proyek Agribisnis, cetakan pertama, penerbit Andi Yogyakarta

Atik Noviani, 2010. Analisis UsahaIndustri Kerupuk Krecek Pati Skala Rumah Tangga Di Kabupaten Klaten.surakarta 
Syarifah Aini dan Erlin Widya Fatmawati, 2017. Analisis Usaha Home Industri Kerupuk Rambak

Journal Viabel Pertanian. (2017), 11(2) 35-45

Bagus, I Gusti Udayana.2011.Peran Agroindustri dalam Pembangunan Pertanian. Edisi 44. http://repository.warmadewa.ac.id/29/1/18-37-1-PB.pdf.

Gustina Siregar, Salman, Lena Wati, 2014. Strategi Pengembangan Usaha Tahu Rumah Tangga. Sumatra Utara

Harianto, B. 2008. 22 Peluang Bisnis Makanan Untuk Home Industry. PT. Agromedia Pustaka. Jakarta.

Henning pury asanti, 2011. Analisis Kelayakan Finansial Usaha Pengolahan Buah. Jakarta

Jamil Mashadi, 2015. Profil Wilaya Kecamatan Kanigoro.

Kusumaningtyas, A. 2008. Analisis Usaha Pembuatan Soun di Desa Manjung Kecamatan Ngawen Kabupaten Klaten. Skripsi Fakultas Pertanian. UNS. Surakarta

Rina Kusrina,2011. Analisis Kelayaka Usaha Pengolahan Kerupuk Perusahaa Kerupuk Cap Dua Gajah .Bogor

Riyanto, B. 2001. Dasar-dasar Pembelanjaan Perusahaan edisi IV BPFE. Yogyakarta

Sari Diwanti Putri,2016. Profil Kota Kabupaten Blitar. Undergraduated Student Of Urban and Regional Planning Institute Technology of sepuluh Nopember

Soekartawi.2001. AgribisnisTeoridanAplikasinya.PT Raja GrafindoPersada. Jakarta

Soekartawi. 2003. TeoriEkonomiProduksi. PT Raja GrafindoPersada. Jakarta 